Objectives To explore the degree of ACPA epitope spreading prior to onset of clinical RA and the pattern of auto-antigen reactivity at the beginning of the immune response.

Methods Multiple serial serum samples of 79 RA patients who had donated blood before disease onset were available for analysis. 47 patients tested ACPA (anti-CCP2) positive prior to the onset of clinical RA. Of these patients a median of 6 (IOR 4-9) sequential pre-RA sera spaced 1-2 years apart were tested for reactivity to five distinct citrullinated peptides in an ELISA. Two fibrinogen peptides, 1 vimentin, $1 \alpha$-enolase and 1 cyclic citrullinated peptide (CCP1) were tested.

Results Four out of 47 ACPA positive patients (9\%) did not show reactivity to any peptide. In 23 ACPA positive patients seroconversion from ACPA absence to ACPA presence was observed. In $16(70 \%)$ of these patients, the immune response started with reactivity towards one peptide, without preference for a particular peptide. In two patients $(9 \%)$ it started with two peptides, in three $(13 \%)$ it started with three peptides and in two $(9 \%)$ it started with four peptides. The number of recognised peptides increased over time, without a dominant epitope spreading pattern. Median titres of all measured ACPA increased over time in a biphasic manner.

Conclusion ACPA epitope spreading occurs over several years prior to onset of clinical RA. None of the tested auto-antigens is solely responsible for the initial auto-immune response. ACPA epitope spreading is a random process. ACPA titers increase in a biphasic way, suggesting a 'second event' a few years before diagnosis of RA.

\section{A2 DEVELOPMENT OF THE ANTICITRULLINATED PEPTIDE ANTIBODY REPERTOIRE PRIOR TO THE ONSET OF RHEUMATOID ARTHRITIS}

L A van de Stadt, ${ }^{1,2}$ M H M T de Koning, ${ }^{1}$ R J van de Stadt, ${ }^{1}$ G Wolbink, ${ }^{1,2}$ B A C Dijkmans, ${ }^{1,4}$ D Hamann, ${ }^{3}$ D van Schaardenburg',4 ${ }^{1}$ Jan van Breemen Institute, Department of Rheumatology, Amsterdam, Netherlands; ${ }^{2}$ Sanquin Research and Landsteiner Laboratorium, Academic Medical Center, Amsterdam, Netherlands; ${ }^{3}$ Sanquin Diagnostic Services, Amsterdam, Netherlands; ${ }^{4}$ VU University Medical Center, Department of Rheumatology, Amsterdam, Netherlands

10.1136/ard.2010.149096.2

Background Anticitrullinated protein antibodies (ACPA) probably play a pathogenic role in rheumatoid arthritis (RA). The ACPA response is already expanded before the first symptoms of RA and hardly changes thereafter. 